\title{
Zu Genesios.
}

In den Byzantinischen Studien p. $118 \mathrm{ff}$. hat Ferd. Hirsch den Historiker Genesios mit einem gleichnamigen Manne zu identifizieren gesucht, welcher in mehreren aufs nächste verwandten Chroniken $^{1}$ ) als Sohn eines vornehmen Armeniers Konstantin genannt wird, der als Oberst der kaiserlichen Leibgarde an einem Wettrennen teilnahm, das zwischen der am 1. Sept. 866 erfolgten Geburt des späteren Kaisers Leo VI und der Ermordung des Kaisers Michael III am 23. Sept. 867 stattfand. $^{2}$ ) Die Kombination von Hirsch beruht darauf, dafs der Bistoriker Genesios diesen Konstantin, der von den übrigen Chronisten nicht weiter erwähnt wird, in seinem Werke ganz besonders hervorhebt und viel von ihm zu erzählen weifs, was auf persönliche warme Teilnahme eines nahe Verwandten schliefsen lasse. Zieht man die relative Seltenheit des Namens Genesios in Betracht, so hat die Kombination unleugbar etwas Bestechendes. Als mẹhr als eine glückliche Vermutung kann man diese Annahme allerdings nicht bezeichnen; denn wenn Hirsch versucht hat, derselben den Stempel eines Beweises aufzudrücken, indem er der Kette seiner Schlufsfolgerungen das Glied einfügt: „Wenn wir wissen, dals dieser Sohn des Konstantin ein Geschichtswerk geschrieben hat", so hat Wäschke im Philologus Bd. 37 p. 268 ff. darauf aufmerksam gemacht, dafs wir darüber gar keine Überlieferung haben. Derselbe hat aber auch hervorgehoben, auf wie erhebliche chronologische Bedenken diese Kombination stölst, wie unglaublich, ja beinahe unmöglich es ist, dafs der Sohn eines Mannes, der in den Jahren 866-867 einen der wichtigsten Vertrauensposten inne hatte und wahrscheinlich bald darauf starb, da er während der Regierung des Basilios, dessen Verwandter er war, nicht mehr erwähnt wird, ca. 80 Jabre später ein Geschichtswerk verfalst habe. Diese

1) Zu den bei Hirsch angefïhrten Stellen kommen die Fortsetzung des Georgios Monachos in der Redaktion des Laurentianus plut. LXX cod. 11 und die

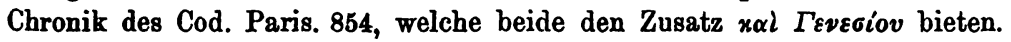

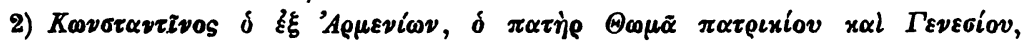

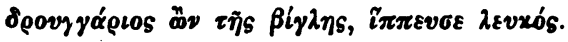


Bedenken werden verstärkt durch eine später bekannt gewordene Notiz, die man mit grofser Wahrscheinlichkeit auf diesen Genesios, Sohn des Konstantin, beziehen darf. Unter den Korrespondenten und nahen Freunden des Diplomaten Leon ${ }^{1}$ ), dessen Briefe von Sakkelion im

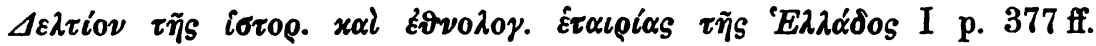
herausgegeben sind, begegnen wir denselben beiden Namen Thomas und Genesios, deren Inhaber mit den höchsten Würden bekleidet sind, wie wir es zu jener Zeit von den Söhnen des Konstantin, den Verwandten der herrschenden Dynastie, voraussetzen dürfen. Die Wahrscheinlichkeit, dafs diese beiden Männer mit den Söhnen des Konstantin identisch sind, wächst dadurch, dals auch Leon sich rühmen durfte, in doppelter Weise dem Kaiserhause verwandtschaftlich nahe zu stehen. Danach wäre jener Genesios a. 906, als Leon seine Gesandtschaftsreise im Orient machte, Magister, Anthypatos und Patrikios gewesen, also gewils schon ein Mann in höherem Lebensalter, ganz wie wir es nach den voraussichtlichen Altersverhältnissen seines Vaters erwarten durften.

Eine Möglichkeit nun, den Kern der Hirschschen Kombination zu retten und eine befriedigende Lösung der chronologischen Frage zu finden, bietet die Chronik des Cod. Vat. gr. 163. Während sie sonst jenes Wettrennen in wörtlicher Ûbereinstimmung mit den übrigen Chroniken schildert, hat sie gerade in den zur Diskussion stehenden

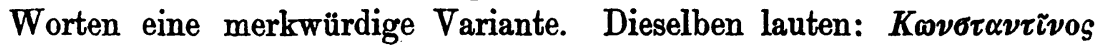

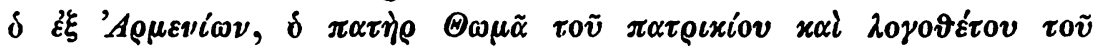

1) Beilüufig möchte ich hier bemerken, dafs bei Krumbacher B. L.-G. ${ }^{2}$ p. 722 die Person dieses Diplomaten jrrig mit der des Leon Philosophos, Professors an der Hochschule von Konstantinopel, identifiziert wird. Ich habe im Kommentar zur Vita Euthymii p. 189 ff. über diesen Mann, seine Schicksale und seine litterarische Thätigkeit eingehender gehandelt und nachgewiesen, dals er mit dem viel genannten und von Krumbacher p. 725 in anderm Zusammenhang beiläufig erwähnten Leon Choirosphaktes identisch ist. Es ist unmöglich, dafs der mit dem Ehren-

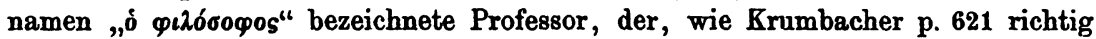
angiebt, unter den Kaisern Theophilos (829-42) und Michael III (842-67) seine Blütezeit hatte und a. 840-43 Metropolit von Thessalonike war (Hauptstelle über ihn Theoph. Cont. p. 185 f.), noch in den Jahren 905-6 eine beschwerliche zweijährige Gesandtschaftsreise in den Orient machen, a. 913 sich an einem Aufstande beteiligen und ca. a. 920 ein Gedicht auf die Gemahlin des Kaisers Konstantin Porphyrogennetos verfassen konnte. Auch Wolters, Rhein. Mus. 38 p. 115 f., scheidet bei der Behandlung der unter Leons Namen überlieferten Epigramme richtig den älteren Philosophen von dem jüngeren Magister. Wohl mit Recht

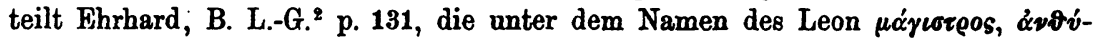

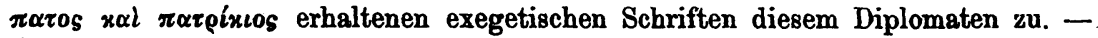
Utber den ebenfalls schriftstellerisch thätigen Leon Katakylas (Krumb. p. 723 A. 2) habe ich Vita Euthymii p. 140 gehandelt. 


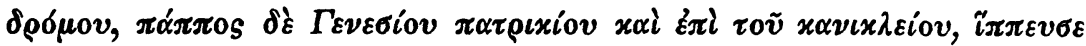

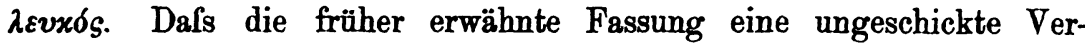
stümmelung dieser Worte sei, ist völlig ausgeschlossen, der Verfasser der Chronik des Vat. 163 hat vielmehr wiederholt den ihm vorliegenden Text durch Nachrichten über seine Zeitgenossen erweitert und verändert, und zu diesen Veränderungen gehört auch diese Stelle. An der Richtigkeit dieser so gefafsten genealogischen Notiz kann an sich kein '/weifel sein, sie wird aber auch noch dadurch bestätigt, dafs wenigstens für einen Punkt derselben, dals nämlich jener Thomas die Würde des Logotheten erlangte, aus anderen Nachrichten der Beweis zu erbringen ist. Die Vita Euthymii XVI 9 erwähnt ihn als solchen: $\delta$

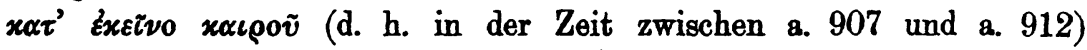

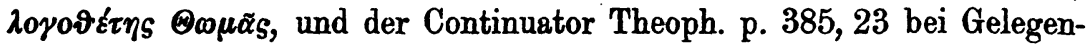
heit der Rebellion des Konstantinos Dux a. 913. Wir können also ein vornehmes Geschlecht, dessen dauernder Besitz hoher Ehrenstellen sich aus der Verwandtschaft mit dem Herrscherhause erklärt, durch drei Generationen hindurch verfolgen:

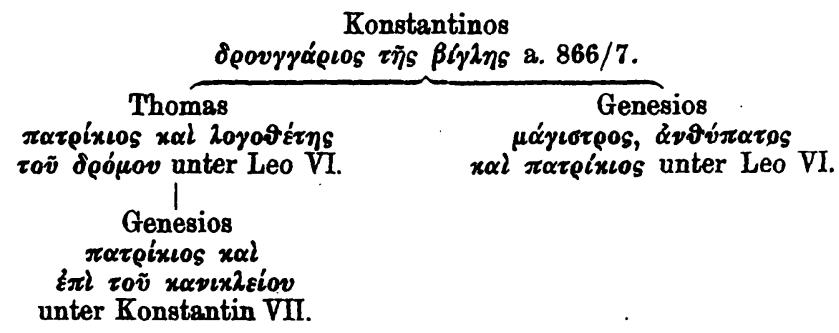

Dafs dieser jüngere Genesios, der Sohn eines Mannes, der in den ersten Jahrzehnten des 10. Jahrhunderts auf der Höhe seines Lebens stand, 'um die Mitte dieses Jahrhunderts in einem Alter stehen konnte, welches ihm noch die Abfassung eines Geschichtswerks gestattete, liegt auf der Hand, wenngleich er voraussichtlich damals bereits in vorgerückteren Jahren war. Der Umstand, dafs der Schlufsteil des Werkes, die Biographie des Kaisers Basilios, weit dürftiger und unvollkommener ausgefallen ist als das Utbrige, und dafs der Kaiser Konstantin Porphyrogennetos einen anderen Autor mit derselben Aufgabe betraute, die er dem Genesios gestellt hatte, erklärt sich eben wohl am besten durch die Annahme, dals der alternde Genesios gestorben sei, bevor er sein Werk zu rechter Vollendung hatte bringen können. Nehmen wir an, dieser jüngere Genesios sei mit dem Historiker identisch, so erklärt sich ebensogut bei dem Enkel, wie nach der Hirschschen Kombination bei dem Sohne, die lebhafte Teilnahme für jenen Konstantin, der sein Grofsvater war und den Glanz seines Geschlechtes begründet hatte. 
Ganz hinfällig ist der weitére von Wäschke gegen Hirsch erbnbene Einwand, dals es auffällig sei, dals nur Konstantin und nicht auch dessen Söhne dieses Interesse des Historikers Genesios erweckt hätten. In der von Genesios behandelten Periode waren diese eben noch junge Leute in den Anfängen ihrer Laufbahn, von deren Thaten damals nichts zu berichten war.

Wenn man somit nicht mit der vollen Sicherheit eines Beweises sagen kann, dafs der jüngere Genesios, Enkel des Armeniers Konstantin, das von einem Autor dieses Namens herrührende Geschichtswerk verfafst habe, so ist doch mit Wahrscheinlicheit anzunehmen, dafs der Kaiser Konstantin diesen seinen Verwandten, der ihm auch in seiner

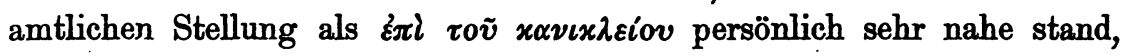
damit betraut habe, das Werk des Theophanes, gleichfalls eines Verwandten des kaiserlichen Hauses, fortzuführen.

Breslau.

c. de Boor. 